\title{
Dot Locations Learning
}

National Cancer Institute

\section{Source}

National Cancer Institute. Dot Locations Learning. NCI Thesaurus. Code C120323.

A component of the Children's Memory Scale. A child is presented with an array of dots (6 or 8 positions depending upon the child's age), which is learned over 3 trials. A distractor array is then presented. The child is then asked to reproduce the initial array either immediately, or following a 30 minute delay. 